\title{
KEGIATAN MENTORING DALAM UPAYA PENINGKATAN HASIL BELAJAR MATA KULIAH PROFESI PENDIDIKAN
}

\author{
Elvi Mailani \\ Surel: elvimailani@gmail.com
}

\begin{abstract}
ABSTRAK
Penelitian ini bertujuan untuk meningkatkan hasil belajar mahasiswa PGSD FIP UNIMED pada mata kuliah profesi pendidikan melalui kegiatan mentoring (pendampingan). Metode pada penelitian ini menggunakan teknik analisis dekriptif kualitatif. Hasil penelitian dapat dilihat dari rata-rata nilai hasil belajar mahasiswa pada saat pratindakan ketuntasan klasikal 29,7\% dengan rata-rata 77,7 , pada siklus I mengalami peningkatan hasil ketuntasan klasikal belajar mahasiswa yang menjadi $6,79 \%$ dengan rata-rata 82,8 dan meningkat lagi menjadi $89,1 \%$ dengan rata-rata 86 pada siklus II. Berdasarkan dari keterangan tersebut dapat disimpulkan bahwa penelitian dengan menggunakan kegiatan mentoring (pendampingan) dapat meningkatkan hasil belajar mahasiswa pada mata kuliah profesi pendidikan.
\end{abstract}

\section{Kata Kunci : Hasil Belajar, Profesi Pendidikan, Mentoring}

\section{PENDAHULUAN}

Pendidikan merupakan sebuah aktivitas yang sangat penting dalam upaya pengembangan sumber daya manusia dan merupakan kebutuhan dasar bagi seluruh lapisan masyarakat Indonesia yang ingin maju. Pendidikan secara formal dimulai dari jenjang taman kanak-kanak sampai dengan perguruan tinggi merupakan bentuk usaha yang dilakukan oleh manusia dalam upaya meningkatkan kompetensi dan mencari jati diri dari setiap insan. Pendidikan pada masa sekarang ini semakin tergantung pada tingkat kualitas, antisipasi dari para guru untuk menggunakan berbagai sumber yang tersedia, dalam upaya mengatasi permasalahan yang dihadapi siswa untuk mempersiapkan pembelajaran yang dapat menumbuhkan cara berfikir mahasiswanya menjadi lebih kritis dan kreatif.

Perkembangan ilmu

pengetahuan yang semakin cepat dalam era globalisasi dan era reformasi merupakan salah satu ciri utama masyarakat masa depan. Kajian masyarakat masa depan semakin penting jika diingat bahwa pendidikan selalu merupakan penyiapan peserta didik bagi peranannya di masa yang akan datang. Mahasiswa PGSD FIP UNIMED sebagai calon guru sekolah dasar yang bertugas mempersiapkan, menguasai dan mengajakankan semua mata pelajaran yang ada di sekolah dasar perlu dibenahi dengan kemampuan disiplin ilmu agar dapat mengantisipasi perkambangann ilmu dan teknologi. Profesi kependidikan merupakan mata kuliah yang harus 
diikuti oleh setiap mahasiswa PGSD FIP UNIMED. Dengan mata kuliah ini diharapkan lulusan PGSD FIP UNIMED akan memahami tugas dan fungsinya sebagai seorang pendidik yang berada ditengah-tengah masyarakat luas kelak setelah mereka selesai menempuh pendidikannya di perguruan tinggi. Mahasiswa PGSD FIP UNIMED sebagai calon guru sekolah dasar yang bertugas mempersiapkan, menguasai dan mengajarkan semua mata pelajaran yang ada di sekolah dasar. Mahasiswa PGSD FIP UNIMED kelak diharapkan menjadi guru dapat mengayomi serta mampu menjadi inspirasi dalam proses pembelajaran bagi guru-guru yang lain. Proses pembelajaran yang selama ini masih terkesan satu arah dan konvensional setidaknya akan dapat dirubah oleh lulusan PGSD FIP UNIMED dengan bekal ilmu yang diperolehnya saat berada dibangku perkuliahan. Profesi guru yang selama ini dipandang rendah oleh sebagian orang akan menjadi profesi yang membanggakan dan dicintai oleh guru itu sendiri ketika dia sadar betapa mulia profesi yang mereka pilih tersebut.

Melihat pentingnya mata kuliah profesi kependidikan ini bagi mahasiswa PGSD FIP UNIMED, maka perlu dirancang strategi yang dilakukan oleh dosen saat mengajar di dalam kelas agar proses perkuliahan menjadi lebih menarik sehingga motivasi dan semangat mahasiswa PGSD FIP UNIMED untuk mengikuti mata kuliah profesi keendidikan menjadi lebih baik dan meningkat.sehingga mahasiswa mampu memahami kompetensi yang terdapat dalam mata kuliah profesi kependidikan tersebut. Namun berdasarkan hasil evaluasi diri ternyata pemahaman dan ketertarikan mahasiswa PGSD FIP UNIMED terhadap mata kuliah profesi kependidikan tergolong rendah jika dibandingkan dengan ketertarikan dan pemahaman mahasiswa terhadap mata kuliah yang lain.

Berdasarkan apa yang dilihat selama ini dalam menyampaikan mata kuliah profesi pendidikan dosen lebih sering menggunakan metode ceramah dan akhirnya mahasiswa diberikan tugas untuk dikerjakan secara kelompok dan dipresentasekan. Akibatnya mahasiswa kurang aktif dalam pembelajaran dan minat siswa terhadap mata kuliah profesi pendidikan juga menjadi rendah. Aktivitas yang dilakukan mahasiswa pada proses perkuliahan terbatas pada mendengarkan penjelasan guru, mencatat, dan mengerjakan tugas dalam kelompok. mahasiswa juga belum terbiasa untuk memecahkan masalah . curah pendapat apalagi melakukan debat atau argumentasi terhadap sebuah konsep materi yang sedang dipelajari. Mahasiswa lebih cenderung menerima pengetahuan yang sudah diberikan oleh guru saja.

Selain itu, kemampuan dosen juga dalam menerapkan metode 
pembelajaran sangat terbatas dan tidak berkembang sesuai dengan perkembangan dinamika kebutuhan mahasiswa. Artinya ketika mengajar seorang dosen kebanyakan masih tetap mempertahankan metode mengajar yang konservatif yaitu ceramah dan memberi tugas kepada mahasiswa

Berdasarkan dari permasalahan tersebut di atas, maka peneliti tertarik untuk melakukan penelitian yang dapat meningkatkan hasil belajar pada mata kuliah profesi pendidikan bagi mahasiswa PGSD FIP UNIMED. Adapun judul penelitian yang dipilih adalah "Upaya meningkatkan hasil belajar pada mata kuliah profesi pendidikan melalui kegiatan mentoring (pendampingan) mahasiswa PGSD FIP UNIMED".

Dari latar belakang masalah yang dijumpai peneliti, dan sejalan dengan pendapat Soejono (2004:4) adapun yang menjadi identifikasi masalah dalam penelitian ini adalah sebagai berikut :

1. Cara dosen mengajar mata kuliah profesi pendidikan yang masih tidak menarik bagi mahasiswa.

2. Dosen tidak mampu merancang proses pemebelajaran yang dapat memotivasi mahasiswa agar terlibat aktif di dalamnya.

3. Sikap mahasiswa terhadap mata kuliah profesi pendidikan tidak menyenangkan, cenderung membencinya.

Berdasarkan hasil identifikasi masalah dan dengan mempertimbangkan waktu, tenaga dan biaya yang tersedia, penelitian tindakan kelas (PTK) ini hanya membatasi masalah pada peningkatan hasil belajar pada mata kuliah profesi pendidikan mahasiswa PGSD FIP UNIMED melalui kegiatan mentoring (pendampingan).

Adapun yang menjadi rumusan masalah pada penelitian ini adalah : " apakah melalui kegiatan mentoring (pendampingan) dapat meningkatkan hasil belajar pada mata kuliah profesi pendidikan mahasiswa PGSD FIP UNIMED? “

Adapun tujuan dari penelitian ini adalah : untuk meningkatkan hasil belajar pada mata kuliah profesi pendidikan mahasiswa PGSD FIP UNIMED melalui kegiatan mentoring (pendampingan).

Penelitian ini diharapkan dapat bermanfaat sebagai berikut :

1. Bagi mahasiswa

a. Penelitian ini bermanfaat bagi mahasiswa karena dapat meningkatkan hasil belajar pada mata kuliah profesi pendidikan.

b. Memberi peluang kepada mahasiswa untuk lebih aktif mengembangkan potensi dirinya terutama dalam memahami profesi yang akan ditekuninya kelak.

2. Bagi dosen

a. Meningkatkan kualitas dosen dalam melaksanakan tugas mengajar terutama dalam 
mengajar pada mata kuliah profesi pendidikan.

b. Merangsang teman dosen yang lain untuk melakukan pembelajaran yang kreatif dan menyenangkan bagi mahasiswa.

3. Bagi Universitas

a. Meningkatkan hasil belajar pada mata kuliah profesi pendidikan sehingga mampu bersaing dengan mata kuliah yang lain.

b. Penelitian ini bermanfaat bagi universitas karena dapat memberi masukan atau sumbangan penelitian bagi peneliti lain yang melakukan Penelitian Tindakan Kelas (PTK).

\section{METODE PENELITIAN}

Subjek pada penelitian ini adalah mahasiswa semester VI PGSD FIP UNIMED Jln. William Iskandar Pasar V Medan Estate. Waktu pelaksanaannya penelitian dimulai pada bulan Mei 2016 s/d Oktober 2016.

Penelitian yang penulis lakukan ini adalah penelitian tindakan kelas (PTK), karena permasalahan yang diangkat adalah permasalahan yang dijumpai langsung oleh penulis ketika mengajarkan mata kuliah profesi pendidikan. Model Penelitian Tindakan kelas yang dipakai adalah model Lewins. Penelitian ini direncakan dilaksanakan sebanyak 2 siklus, dan dalam setiap siklusnya terdapat kegiatan : 1. Perencanaan, 2. Pelaksanaan, 3. Pengamatan, 4. Refleksi. Adapun alur model penelitian tindakan kelas (PTK) yang dilakukan oleh peneliti adalah sebagai berikut:

Pada tahap perencanaan ini penelitian menentukan langkahlangkah sebagai berikut:

a) Menyusun jadwal dan merencanakan kegiatan pendampingan

b) Mempersiapkan materi pada mata kuliah profesi pendidikan yang akan dipelajari oleh mahasiswa

Dalam tahap pelaksanaan kegiatan penelitian dilaksanakan dalam 2 kali pertemuan sesuai dengan jadwal yang telah ditetapkan oleh peneliti bersama dengan mahasiswa yang menjadi subjek penelitian. langkah-langkah yang ditempuh adalah sebagai berikut :

a. Mengumpulkan mahasiswa dan melakukan curah pendapat tentang kendala yang dirasakan dalam mempelajari mata kuliah profesi pendidikan (di luar perkuliahan)

b. Membahas tentang materi yang akan disampaikan pada tatap muka perkuliahan berikutnya (luar perkuliahan).

c. Menugaskan mahasiswa secara bergantian untuk menyampaikan materi tentang mata kuliah profesi pendidikan yang telah dipahaminya saat tatap muka perkuliahan. 
d. Curah pendapat dan diskusi terhadap materi yang baru dibahas.

Pengamatan dilakukan oleh peneliti pada saat mahasiswa secara bergantian menyampaikan konsep materi mata kuliah profesi pendidikan disampaikan. Peneliti mengamati apa kekurangan dan kelemahan setiap mahasiswa terutama saat mahasiswa berargumentasi satu dengan yang lain saat curah pendapat berlangsung.

Tahap ini merupakan tahap akhir setiap siklus, peneliti menyimpulkan dan mengevaluasi jalannya kegiatan yang telah dilaksanakan dengan maksud untuk mengetahui dan untuk menemukan hal-hal yang terjadi selama kegiatan berlangsung untuk mengetahui letak keberhasilan dan hambatan yang baru saja dilaksanakan sebagai bahan masukan pada perencanaan siklus berikutnya. Pada saat ini peneliti juga mengumpulkan mahasiswa untuk melakukan curah pendapat dan berdiskusi tentang apa saja kendala yang masih dirasakan, apa yang belum dipahami dan untuk menyusun jadwal pendampingan berikutnya.

Tehnik pengumpulan data yang digunakan dalam penelitian ini adalah tes, wawancara dan observasi. Tes dilakukan diakhir setiap siklus dengan tujuan ingin melihat kemampuan siswa dalam menjawab soal soal yang berhubungan dengan mata kuliah profesi pendidikan setelah mendapatkan tindakan mentoring (pendampingan).
Wawancara dilakukan diakhir penelitian untuk mendengar sejauh mana manfaat mentoring (pendampingan) ini dirasakan mahasiswa dalam upaya meningkatkan pemahaman mereka terhadap materi pada mata kuliah profesi pendidikan. Sedangkan observasi dilakukan di setiap siklusnya dengan tujuan untuk melihat proses peningkatan keberanian, semangat dan peningkatan pemahaman mahasiswa terhadap materi pada mata kuliah profesi pendidikan.

Hasil analisis tes dihitung dengan menggunakan persen atau disebut percentages correction. Rumus penelitian adalah sebagai berikut :

$$
\mathbf{N P}=\frac{\mathrm{R}}{----\times 100}
$$

NP : Nilai Persen yang dicari

$\mathrm{R} \quad$ : Skore Perolehan

SM : Skore Maksimum

100 : Bilangan tetap

Indikator keberhasilan penelitian ini adalah apabila rata rata presentase hasil tes mahasiswa pada mata kuliah profesi pendidikan mencapai $85 \%$ dari seluruh jumlah mahasiswa yang menjadi sampel pada penelitian ini.

\section{HASIL DAN PEMBAHASAN}

Deskripsi hasil penelitian yang dimaksud adalah hasil penelitian pada 
pratindakan dan kemudian hasil penelitian pada siklus I dan dilanjutkan pada hasil penelitian pada siklus II yang meliputi deskripsi hasil penilaian terhadap kemampuan mahasiswa pada mata kuliah profesi pendidikan setelah dilakukan kegiatan mentoring (pendampingan).

Kegiatan pra tindakan dilakukan untuk mengetahui sejauh mana pemahaman dan kemampuan mahasiswa PGSD FIP UNIMED dalam memahami materi pada mata kuliah profesi pendidikan, mahasiswa PGSD FIP UNIMED yang diteliti berjumlah 37 orang dan hasil pratindakan dapat dilihat pada tabel berikut ini:

Tabe1 4.1 Persentase Kemampuan Mahasiswa Pada Matakuliah Profesi Pendidikan Pra Siklus

\begin{tabular}{|c|c|c|c|}
\hline NO & Nama Mahasiswa & $\mathrm{F} 1$ & HURUF \\
\hline 1 & ADE CANTIK & 87 & $\mathrm{~B}$ \\
\hline 2 & ANNISA RIZKI UTAMI & 84 & B \\
\hline 3 & AYU LESTARI SAMBAS & 79 & $\mathrm{C}$ \\
\hline 4 & $\begin{array}{l}\text { DASMANSYAH } \\
\text { HUTAPEA }\end{array}$ & 89 & B \\
\hline 5 & DINDA DHIYANIRA & 77 & $\mathrm{C}$ \\
\hline 6 & $\begin{array}{l}\text { DWI PUTRI MARDINA } \\
\text { WANTI }\end{array}$ & 79 & $\mathrm{C}$ \\
\hline 7 & EKA WULANDARI & 89 & B \\
\hline 8 & $\begin{array}{l}\text { GITAFOR M } \\
\text { SIMAREMARE }\end{array}$ & 80 & B \\
\hline 9 & HANAH MARIA SILAEN & 82 & $\mathrm{~B}$ \\
\hline 10 & ILHAM MAKMUR HSB & 92 & A \\
\hline 11 & INDAH AYU UTARI & 71 & $\mathrm{C}$ \\
\hline 12 & $\begin{array}{l}\text { IRFAN MAHYARUDDIN } \\
\mathrm{Z}\end{array}$ & 91 & A \\
\hline 13 & JAMILATULLAILI HRP & 70 & $\mathrm{C}$ \\
\hline 14 & KARDA LESTARI & 87 & B \\
\hline 15 & $\begin{array}{l}\text { LYDIYA KANDA } \\
\text { BR.GINTING }\end{array}$ & 78 & $\mathrm{C}$ \\
\hline 16 & MALENI & 71 & $\mathrm{C}$ \\
\hline
\end{tabular}

\begin{tabular}{|c|c|c|c|}
\hline 17 & $\begin{array}{l}\text { MEGAWATI } \\
\text { SITUMORANG }\end{array}$ & 75 & $\mathrm{C}$ \\
\hline 18 & $\begin{array}{l}\text { NESTIMALA BANJAR } \\
\text { NHR }\end{array}$ & 76 & $\mathrm{C}$ \\
\hline 19 & NILFA DILIA LUBIS & 78 & $\mathrm{C}$ \\
\hline 20 & NIRWANA HERAWATI & 85 & B \\
\hline 21 & NONI PRASETIA & 73 & $\mathrm{C}$ \\
\hline 22 & NOVA HARLINA & 93 & A \\
\hline 23 & NUR ELFI SYAHRINA & 76 & $\mathrm{C}$ \\
\hline 24 & NUR SA'ADAH & 77 & $\mathrm{C}$ \\
\hline 25 & $\begin{array}{l}\text { OKI RISMAWATI } \\
\text { SIANTURI }\end{array}$ & 71 & $\mathrm{C}$ \\
\hline 26 & PUJI LESTARI & 78 & $\mathrm{C}$ \\
\hline 27 & $\begin{array}{l}\text { RAPIKA NUR } \\
\text { NASUTION }\end{array}$ & 76 & $\mathrm{C}$ \\
\hline 28 & RARA SINTIA LUBIS & 77 & $\mathrm{C}$ \\
\hline 29 & RIFNA FAHIRA & 79 & $\mathrm{C}$ \\
\hline 30 & $\begin{array}{l}\text { RISKA AGINTA BR. } \\
\text { SITEPU }\end{array}$ & 76 & $\mathrm{C}$ \\
\hline 31 & ROMIAN SIAHAAN & 79 & $\mathrm{C}$ \\
\hline 32 & RULLI FADHIL HSB & 77 & $\mathrm{C}$ \\
\hline 33 & $\begin{array}{l}\text { SEKAR DRYA FAJRIN } \\
\text { N. }\end{array}$ & 77 & $\mathrm{C}$ \\
\hline 34 & $\begin{array}{l}\text { SILVINA RICEA BR. } \\
\text { GINTING }\end{array}$ & 71 & $\mathrm{C}$ \\
\hline 35 & SINTA ANGGREINI & 75 & $\mathrm{C}$ \\
\hline 36 & $\begin{array}{l}\text { SRI WAHYUNI } \\
\text { GULTOM }\end{array}$ & 78 & $\mathrm{C}$ \\
\hline 37 & VINY SARTIKA LUBIS & 73 & $\mathrm{C}$ \\
\hline
\end{tabular}

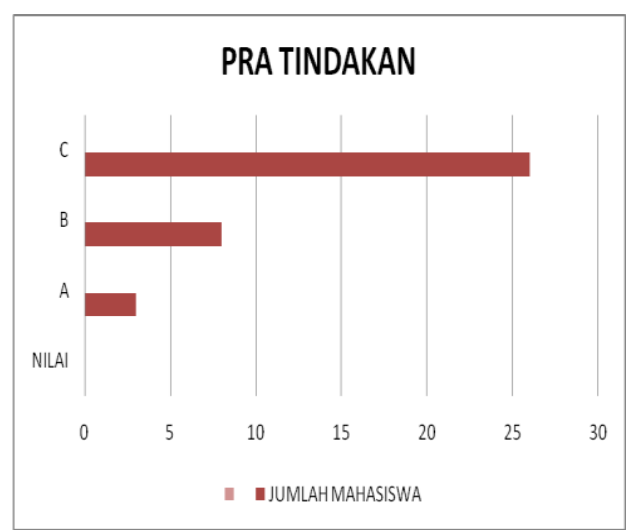

Gambar 4.1. Hasil Belajar Mahasiswa Pada Pratindakan 
Dari hasil kegiatan pra tindakan yang telah dilakukan dan digambarkan dalam tabel dan diagram di atas terlihat bahwa kemampuan mahasiswa PGSD FIP UNIMED dalam memahami materi pada mata kuliah profesi pendidikan masih sangat rendah. Dari 37 mahasiswa hanya 11 mahasiswa $(29,7 \%)$ yang mendapat nilai baik, sementara selebihnya atau sebanyak 26 mahasiswa $(70,1 \%)$ masuk ke dalam kategori tidak baik.

Setelah melihat hasil pratindakan (keadaan awal) kemampuan mahasiswa dalam memahami materi pada mata kuliah propesi pendidikan seperti yang telah dipaparkan, perlu dilakukan sebuah tindakan agar dapat meningkatkan kemampuan mahasiswa dalam memahami materi pada mata kuliah profesi Pendidikan Tindakan yang dilakukan adalah kegiatan mentoring (pendampingan) yang harus dilakukan oleh dosen mata kuliah profesi pendidikan.

Siklus I merupakan pemberlakuan awal penelitian dengan melakukan kegiatan mentoring (pendampingan) yang dilakukan kepada mahasiswa. Tindakan siklus ini dilakukan sebagai upaya untuk memperbaiki dan memecahkan masalah yang muncul pada pratindakan.

Kegiatan siklus I dilakukan dengan menggunakan kegiatan mentoring yang dilakukan oleh dosen pengampu mata kuliah profesi pedidikan dengan sebelumnya menyampaikan rencana kegiatan dalam mentoring kepada seluruh mahasiswanya. Kegiatan mentoring (pendampingan) yang dilakukan pada siklus I bertujuan untuk membantu siswa memahami berbagai materi yang berhubugan dengan mata kuliah profesi pendidikan. Kegiatan mentoring (pendampingan) dilakukan oleh dosen diluar dan di dalam kegiatan perkuliahan. Jumlah mahasiswa yang mengikuti siklus I berjumlah 37 mahasiswa dengan aspek pendampingan meliputi materimateri yang sedang dan akan dipelajari oleh mahasiswa pada mata kuliah profesi pendidikan. Hasil tes kemampuan mahasiswa dalam memahami materi pada mata kuliah profesi pendidikan setelah dilakukan kegiatan mentoring (pendampingan) dapat dilihat pada tabel berikut :

Tabel 4.2 Hasil Belajar Mahasiswa Siklus I

\begin{tabular}{|c|l|c|c|}
\hline NO & Nama Mahasiswa & F2 & HURUF \\
\hline 1 & ADE CANTIK & 92 & A \\
\hline 2 & $\begin{array}{l}\text { ANNISA RIZKI } \\
\text { UTAMI }\end{array}$ & 75 & $\mathrm{C}$ \\
\hline 3 & $\begin{array}{l}\text { AYU LESTARI } \\
\text { SAMBAS }\end{array}$ & 78 & $\mathrm{C}$ \\
\hline 4 & $\begin{array}{l}\text { DASMANSYAH } \\
\text { HUTAPEA }\end{array}$ & 90 & $\mathrm{~A}$ \\
\hline 5 & DINDA DHIYANIRA & 78 & $\mathrm{C}$ \\
\hline 6 & $\begin{array}{l}\text { DWI PUTRI } \\
\text { MARDINA WANTI }\end{array}$ & 78 & $\mathrm{C}$ \\
\hline 7 & EKA WULANDARI & 86 & $\mathrm{~B}$ \\
\hline 8 & $\begin{array}{l}\text { GITAFOR M } \\
\text { SIMAREMARE }\end{array}$ & 77 & $\mathrm{C}$ \\
\hline 9 & $\begin{array}{l}\text { HANAH MARIA } \\
\text { SILAEN }\end{array}$ & 84 & $\mathrm{~B}$ \\
\hline 10 & $\begin{array}{l}\text { ILHAM MAKMUR } \\
\text { HSB }\end{array}$ & 94 & $\mathrm{~A}$ \\
\hline 11 & INDAH AYU UTARI & 81 & $\mathrm{~B}$ \\
\hline 12 & $\begin{array}{l}\text { IRFAN } \\
\text { MAHYARUDDIN Z }\end{array}$ & 94 & $\mathrm{~A}$ \\
\hline
\end{tabular}




\begin{tabular}{|c|c|c|c|}
\hline 13 & $\begin{array}{l}\text { JAMILATULLAILI } \\
\text { HRP }\end{array}$ & 80 & B \\
\hline 14 & KARDA LESTARI & 87 & B \\
\hline 15 & $\begin{array}{l}\text { LYDIYA KANDA } \\
\text { BR.GINTING }\end{array}$ & 78 & $\mathrm{C}$ \\
\hline 16 & MALENI & 85 & B \\
\hline 17 & $\begin{array}{l}\text { MEGAWATI } \\
\text { SITUMORANG }\end{array}$ & 76 & $\mathrm{C}$ \\
\hline 18 & $\begin{array}{l}\text { NESTIMALA } \\
\text { BANJAR NHR }\end{array}$ & 77 & $\mathrm{C}$ \\
\hline 19 & NILFA DILIA LUBIS & 84 & B \\
\hline 20 & $\begin{array}{l}\text { NIRWANA } \\
\text { HERAWATI }\end{array}$ & 85 & B \\
\hline 21 & NONI PRASETIA & 83 & $\mathrm{~B}$ \\
\hline 22 & NOVA HARLINA & 95 & A \\
\hline 23 & $\begin{array}{l}\text { NUR ELFI } \\
\text { SYAHRINA }\end{array}$ & 78 & $\mathrm{C}$ \\
\hline 24 & NUR SA'ADAH & 84 & B \\
\hline 25 & $\begin{array}{l}\text { OKI RISMAWATI } \\
\text { SIANTURI }\end{array}$ & 78 & $\mathrm{C}$ \\
\hline 26 & PUJI LESTARI & 78 & $\mathrm{C}$ \\
\hline 27 & $\begin{array}{l}\text { RAPIKA NUR } \\
\text { NASUTION }\end{array}$ & 76 & $\mathrm{C}$ \\
\hline 28 & $\begin{array}{l}\text { RARA SINTIA } \\
\text { LUBIS }\end{array}$ & 87 & $\mathrm{~B}$ \\
\hline 29 & RIFNA FAHIRA & 94 & A \\
\hline 30 & $\begin{array}{l}\text { RISKA AGINTA BR. } \\
\text { SITEPU }\end{array}$ & 76 & $\mathrm{C}$ \\
\hline 31 & ROMIAN SIAHAAN & 86 & $\mathrm{~B}$ \\
\hline 32 & RULLI FADHIL HSB & 79 & $\mathrm{C}$ \\
\hline 33 & $\begin{array}{l}\text { SEKAR DRYA } \\
\text { FAJRIN N. }\end{array}$ & 86 & B \\
\hline 34 & $\begin{array}{l}\text { SILVINA RICEA BR. } \\
\text { GINTING }\end{array}$ & 79 & $\mathrm{C}$ \\
\hline 35 & SINTA ANGGREINI & 78 & $\mathrm{C}$ \\
\hline 36 & $\begin{array}{l}\text { SRI WAHYUNI } \\
\text { GULTOM }\end{array}$ & 86 & B \\
\hline 37 & $\begin{array}{l}\text { VINY SARTIKA } \\
\text { LUBIS } \\
\end{array}$ & 83 & $\mathrm{~B}$ \\
\hline
\end{tabular}

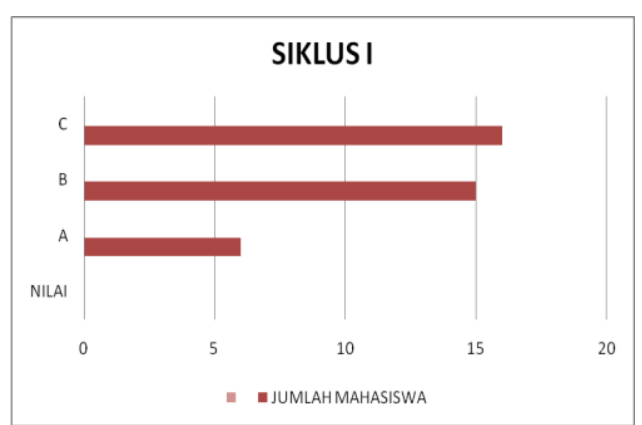

Gambar 4. 2. Hasil Belajar Mahasiswa Siklus I
Setelah siklus I dilaksanakan terlihat peningkatan kemampuan mahasiswa dalam memahami materimateri yang terdapat pada mata kuliah profesi pendidikan yang diberikan oleh dosen. Peningkatan pemahaman mahasiswa pada materi mata kuliah profesi pendidikan ini dapat dilihat dari tabel dan diagram yang tertera di atas. Jika pada pra tindakan jumlah mahasiswa yang memperoleh nilai baik sebanyak 11 mahasiswa $(29,7 \%)$ maka pada siklus I setelah mahasiswa diberikan kegiatan mentoring maka jumlah mahasiswa yang memperoleh nilai pada kategori baik meningkat menjadi 21 mahasiswa $(56,7 \%)$ terjadi peningkatan jumlah mahasiswa yang memperoleh kategori baik sebanyak 10 mahasiswa (27\%). Sedangkan jumlah mahasiswa yang memperoleh nilai kurang baik jika pada pra tindakan berjumlah 26 mahasiswa $(70,1 \%)$. Setelah siklus I dilaksanakan dengan menggunakan kegiatan mentoring, maka terjadi penurunan sebesar $26,9 \%$ dimana dari 26 mahasiswa atau 70,1\% berkurang menjadi 16 mahasiswa atau $43,2 \%$.

Dari paparan di atas terlihat peningkatan pemahaman mahasiswa terhadap materi yang disampaikan oleh dosen mata kuliah profesi pendidikan setelah dilakukan kegiatan mentoring (pendampingan). Peningkatan yang terjadi belum menunjukkan sesuai dengan indikator pencapaian yang telah di tetapkan pada penelitian ini, maka penelitian 
ini harus dilanjutkan pada siklus berikutnya.

Observasi dilakukan dengan bertujuan untuk mengetahui perilaku mahasiswa selama kegiatan mentoring (pendampingan) dilakukan. Baik saat kegiatan tatap muka perkuliahan maupun di luar kegiatan tatap muka perkuliahan. Objek sasaran yang diamati dalam observasi mahasiswa pada kegiatan mentoring (pendampingan) meliputi 5 perilaku positif yang dapat terlihat dari mahasiswa. Adapun objek sasaran perilaku positif meliputi : (a) sikap mahasiswa saat kegiatan mentoring (pendampingan) dilakukan (b) keseriusan mahasiswa dalam menerima kegiatan mentoring (pendampingan) yang dilakukan dosen (c) bentuk partisipasi aktif mahasiswa saat kegiatan mentoring (pendampingan) dilakukan (d) keberanian mahasiswa dalam bertanya dan memecahkan permasalahan saat kegiatan mentoring (pendampingan) dilakukan dan (e) keterbukaan mahasiswa terhadap kelemahan dan kekuatan yang dimilikinya sehubungan dengan materi mata kuliah profesi pendidikan yang diikutinya.

Dari hasil wawancara yang peneliti lakukan dari beberapa pertanyaan yang peneliti terhadap kegiatan mentoring (pendampingan) yang telah dilakukan, secara garis besar dapat diambil kesimpulan bahwa pada siklus I ini dari 37 mahasiswa sebanyak 24 mahasiswa atau $64,8 \%$ menyatakan senang terhadap kegiatan mentoring (pendampingan) yang dilakukan oleh dosen pada materi mata kuliah profesi pendidikan.

Setelah siklus I selesai dilaksanakan dosen bersama dengan mahasiswa melakukan refleksi untuk mengetahui kekuatan dan kelemahan kegiatan mentoring (pendampingan) yang telah diaksanakan pada siklus I. Refleksi ini bertujuan untuk lebih mengoptimalkan kegiatan mentoring (pendampingan) yang akan dilaksanakan pada siklus berikutnya. Hasil refleksi yang telah dilakukan pada siklus I diantaranya: (1) penyusunan jadwal yang belum efektif dengan aktiftas perkuliahan mahasiswa dengan mata kuliah yang lain, (2) ruangan tempat pelaksanaan mentoring yang susah didapat terutama kegiatan mentoring yang dilakukan di luar jam perkuliahan, (3) Kegiatan mentoring (pendampingan) adalah hal yang baru bagi mahasiswa sehingga mahasiswa merasa kurang nyaman dengan kegiatan tersebut, (4) kurang keterbukaan mahasiswa terhadap hal-hal yang belum dikuasainya yang berhubungan dengan materi profesi pendidikan.

Berdasarkan hasil siklus I dan refleksi yang telah dilakukan pada siklus I maka penelitian ini harus dilanjutkan ke siklus II karena hasil pencapaian pada siklus I belum sesuai dengan indikator pencapaian yang telah direncanakan pada penelitian ini. Kegiatan mentoring 
(pendampingan) yang dilakukan pada siklus II sama halnya dengan yang dilakukan pada siklus I. Perbedaan yang terlihat pada kegiatan mentoring (pendampingan) yang dilakukan pada siklus II adalah, jika pada siklus I yang melakukan pendampingan adalah dosen saja, maka pada siklus II dalam melakukan pendampingan, dosen dibantu oleh teman-teman mahasiswa yang telah mendapatkan kategori nilai A pada siklus I. Hal ini dilakukan dengan tujuan bagi mahasiswa yang masih belum paham diharapkan dengan bahasa sesama mahasiswa pemahaman tentang materi pada mata kuliah profesi pendidikan akan lebih muadah dipahami. Sedangkan bagi mahasiswa yang sudah mendapat kategori nilai A dengan dilibatkannya mereka pada kegiatan mentoring (pendampingan) diharapkan pemahaman mereka akan lebih baik lagi.

Setelah kegiatan mentoring (pendampingan) pada siklus II dilaksanakan pemahaman mahasiswa terhadap materi pada mata kuliah profesi pendidikan terlihat jauh meningkat. Peningkatan kemampuan mahasiswa terhadap materi pada mata kuliah pendidikan profesi dapat dilihat pada tabel di bawah ini:

Tabel 4.3 Hasil Belajar Mahasiswa Siklus II

\begin{tabular}{|c|l|c|c|}
\hline NO & Nama Mahasiswa & F3 & HURUF \\
\hline 1 & ADE CANTIK & 95 & A \\
\hline 2 & ANNISA RIZKI & & \\
\hline & UTAMI & 79 & C \\
3 & $\begin{array}{l}\text { AYU LESTARI } \\
\text { SAMBAS }\end{array}$ & 82 & B \\
\hline
\end{tabular}

\begin{tabular}{|c|c|c|c|}
\hline 4 & $\begin{array}{l}\text { DASMANSYAH } \\
\text { HUTAPEA }\end{array}$ & 93 & A \\
\hline 5 & $\begin{array}{l}\text { DINDA } \\
\text { DHIYANIRA }\end{array}$ & 80 & B \\
\hline 6 & $\begin{array}{l}\text { DWI PUTRI } \\
\text { MARDINA WANTI }\end{array}$ & 82 & B \\
\hline 7 & $\begin{array}{l}\text { EKA } \\
\text { WULANDARI }\end{array}$ & 92 & A \\
\hline 8 & $\begin{array}{l}\text { GITAFOR M } \\
\text { SIMAREMARE }\end{array}$ & 82 & B \\
\hline 9 & $\begin{array}{l}\text { HANAH MARIA } \\
\text { SILAEN }\end{array}$ & 91 & A \\
\hline 10 & $\begin{array}{l}\text { ILHAM MAKMUR } \\
\text { HSB }\end{array}$ & 95 & A \\
\hline 11 & $\begin{array}{l}\text { INDAH AYU } \\
\text { UTARI }\end{array}$ & 83 & B \\
\hline 12 & $\begin{array}{l}\text { IRFAN } \\
\text { MAHYARUDDIN } \\
\mathrm{Z}\end{array}$ & 96 & A \\
\hline 13 & $\begin{array}{l}\text { JAMILATULLAILI } \\
\text { HRP }\end{array}$ & 84 & $\mathrm{~B}$ \\
\hline 14 & KARDA LESTARI & 89 & B \\
\hline 15 & $\begin{array}{l}\text { LYDIYA KANDA } \\
\text { BR.GINTING }\end{array}$ & 84 & $\mathrm{~B}$ \\
\hline 16 & MALENI & 90 & A \\
\hline 17 & $\begin{array}{l}\text { MEGAWATI } \\
\text { SITUMORANG }\end{array}$ & 80 & $\mathrm{~B}$ \\
\hline 18 & $\begin{array}{l}\text { NESTIMALA } \\
\text { BANJAR NHR }\end{array}$ & 81 & $\mathrm{~B}$ \\
\hline 19 & $\begin{array}{l}\text { NILFA DILIA } \\
\text { LUBIS }\end{array}$ & 86 & B \\
\hline 20 & $\begin{array}{l}\text { NIRWANA } \\
\text { HERAWATI }\end{array}$ & 90 & A \\
\hline 21 & NONI PRASETIA & 85 & B \\
\hline 22 & NOVA HARLINA & 96 & A \\
\hline 23 & $\begin{array}{l}\text { NUR ELFI } \\
\text { SYAHRINA }\end{array}$ & 82 & $\mathrm{~B}$ \\
\hline 24 & NUR SA'ADAH & 86 & B \\
\hline 25 & $\begin{array}{l}\text { OKI RISMAWATI } \\
\text { SIANTURI }\end{array}$ & 81 & $\mathrm{~B}$ \\
\hline 26 & PUJI LESTARI & 81 & B \\
\hline 27 & $\begin{array}{l}\text { RAPIKA NUR } \\
\text { NASUTION }\end{array}$ & 77 & $\mathrm{C}$ \\
\hline 28 & $\begin{array}{l}\text { RARA SINTIA } \\
\text { LUBIS }\end{array}$ & 91 & $\mathrm{~A}$ \\
\hline 29 & RIFNA FAHIRA & 96 & A \\
\hline 30 & $\begin{array}{l}\text { RISKA AGINTA } \\
\text { BR. SITEPU }\end{array}$ & 78 & $\mathrm{C}$ \\
\hline 31 & $\begin{array}{l}\text { ROMIAN } \\
\text { SIAHAAN }\end{array}$ & 90 & A \\
\hline 32 & $\begin{array}{l}\text { RULLI FADHIL } \\
\text { HSB }\end{array}$ & 81 & $\mathrm{~B}$ \\
\hline 33 & $\begin{array}{l}\text { SEKAR DRYA } \\
\text { FAJRIN N. }\end{array}$ & 90 & A \\
\hline 34 & $\begin{array}{l}\text { SILVINA RICEA } \\
\text { BR. GINTING }\end{array}$ & 82 & B \\
\hline 35 & $\begin{array}{l}\text { SINTA } \\
\text { ANGGREINI }\end{array}$ & 79 & $\mathrm{C}$ \\
\hline 36 & $\begin{array}{l}\text { SRI WAHYUNI } \\
\text { GULTOM }\end{array}$ & 91 & A \\
\hline 37 & $\begin{array}{l}\text { VINY SARTIKA } \\
\text { LUBIS }\end{array}$ & 83 & B \\
\hline
\end{tabular}




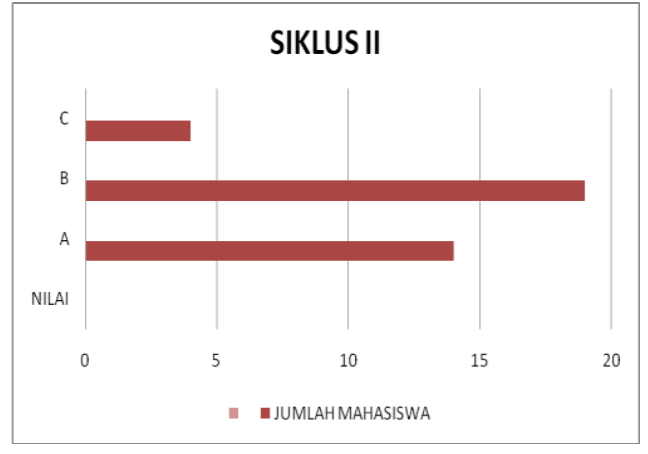

Gambar 4.3. Hasil Belajar Mahasiswa Siklus II

Setelah siklus II dilaksanakan terlihat peningkatan kemampuan mahasiswa dalam memahami materimateri yang terdapat pada mata kuliah profesi pendidikan yang diberikan oleh dosen. Peningkatan pemahaman mahasiswa pada materi mata kuliah profesi pendidikan ini dapat dilihat dari tabel dan diagram yang tertera di atas. Jika pada siklus I jumlah mahasiswa yang memperoleh nilai baik sebanyak 21 mahasiswa $(56,7 \%)$ maka pada siklus II setelah mahasiswa diberikan kegiatan mentoring maka jumlah mahasiswa yang memperoleh nilai pada kategori baik meningkat menjadi 33 mahasiswa $\quad(89,2 \%) \quad$ terjadi peningkatan jumlah mahasiswa yang memperoleh kategori baik sebanyak 12 mahasiswa $(32,4 \%)$ jika dibandingkan dengan siklus I. Sedangkan jumlah mahasiswa yang memperoleh nilai kurang baik jika pada siklus I berjumlah 16 mahasiswa $(43,2 \%)$ setelah siklus II dilaksanakan dengan menggunakan kegiatan mentoring, maka terjadi penurunan sebesar $32,4 \%$ dimana dari
16 mahasiswa $(70,1 \%)$ berkurang menjadi 4 mahasiswa (10,8\%)

Dari paparan di atas terlihat peningkatan pemahaman mahasiswa terhadap materi yang disampaikan oleh dosen mata kuliah profesi pendidikan setelah dilakukan kegiatan mentoring (pendampingan). Peningkatan yang terjadi telah sangat baik dan telah mencapai indikator pencapaian pada penelitian ini. Mengacu kepada indikator pencapaian tersebut maka penelitian ini dikatakan berhasil dan tidak perlu dilanjutkan lagi pada siklus berikutnya.

Observasi pada siklus II dilakukan sama halnya dengan observasi yang dilakukan pada siklus I, observasi dilakukan dengan tujuan untuk mengetahui perilaku mahasiswa selama kegiatan mentoring (pendampingan) dilakukan. Baik saat kegiatan tatap muka perkuliahan maupun diluar kegiatan tatap muka perkuliahan. Objek sasaran yang diamati dalam observasi mahasiswa pada kegiatan mentoring (pendampingan) meliputi 5 perilaku positif yang dapat terlihat dari mahasiswa. Adapun objek sasaran perilaku positif meliputi : (a) sikap mahasiswa saat kegiatan mentoring (pendampingan) dilakukan (b) keseriusan mahasiswa dalam menerima kegiatan mentoring (pendampingan) yang dilakukan dosen (c) bentuk partisipasi aktif mahasiswa saat kegiatan mentoring (pendampingan) dilakukan 
keberanian mahasiswa dalam bertanya dan memecahkan permasalahan saat kegiatan mentoring (pendampingan) dilakukan dan (e) keterbukaan mahasiswa terhadap kelemahan dan kekuatan yang dimilikinya sehubungan dengan materi mata kuliah profesi pendidikan yang diikutinya

Dari hasil wawancara yang peneliti lakukan dari beberapa pertanyaan yang peneliti terhadap kegiatan mentoring (pendampingan) yang telah dilakukan, secara garis besar dapat diambil kesimpulan bahwa pada siklus II ini dari 37 mahasiswa sebanyak 35 mahasiswa atau $94,5 \%$ menyatakan senang terhadap kegiatan mentoring (pendampingan) yang dilakukan oleh dosen pada materi mata kuliah profesi pendidikan.

Adapun hasil peningkatan kemampuan mahasiswa PGSD FIP UNIMED setelah dilakukan kegiatan mentoring (pendampingan) pada mata kuliah profesi pendidikan, dapat dilihat dari tabel di bawah ini:

Tabel 4.4 Peningkatan Kemampuan Mahasiswa Pada Mata Kuliah Profesi Pendidikan

\begin{tabular}{|c|c|c|c|c|}
\hline Tahap & \multicolumn{3}{|c|}{$\begin{array}{c}\text { Jumlah } \\
\text { mahasiswa } \\
\text { Kategori Nilai }\end{array}$} & \% rerata \\
\hline & A & B & C & \\
\hline $\begin{array}{c}\text { Pra } \\
\text { Siklus }\end{array}$ & 3 & 8 & 26 & $\mathbf{7 7 . 7}$ \\
\hline Sikus I & 6 & 15 & 16 & $\mathbf{8 2 , 8}$ \\
\hline Siklus II & 14 & 19 & 4 & $\mathbf{8 6}$ \\
\hline
\end{tabular}

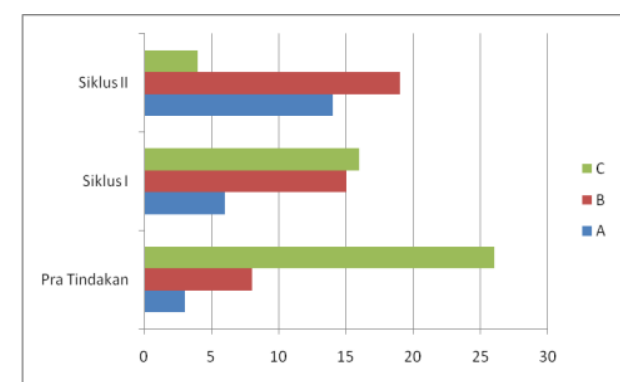

Gambar 4.4 Peningkatan

Kemampuan Mahasiswa Pada Mata Kuliah Profesi Pendidikan

Gambar dan tabel di atas menunjukkan peningkatan kemampuan mahasiswa PGSD FIP UNIMED pada mata kuliah profesi setelah mendapatkan kegiatan mentoring (pendampingan) sebanyak 2 siklus. Dari gambar terlihat peningkatan yang berarti dari jumlah mahasiswa yang mampu memahami materi pada mata kuliah profesi pendidikan dari pra siklus hingga ke siklus II.

Dari gambar di atas terlihat jumlah mahasiswa yang mendapatkan nilai kategori baik jika pada pra tindakan sebanyak 11 mahasiswa $(29,7 \%)$ dan yang memperoleh nilai tidak baik sebanyak 26 mahasiswa $(70,1 \%)$ maka setelah dilaksanakan siklus I mahasiswa yang memperoleh nilai baik meningkat menjadi 21 mahasiswa $(56,7 \%)$ dan mahasiswa yang memperoleh nilai tidak baik berkurang menjadi 16 mahasiswa (43,2\%). Selanjutnya siklus II dilaksanakan dengan hasil jika pada siklus I jumlah mahasiswa yang memperoleh nilai baik sebanyak 21 mahasiswa $(56,7 \%)$ maka pada siklus 
II meningkat menjadi 33 mahasiswa $(89,2 \%)$ sedangkan mahasiswa yang memperoleh nilai tidak baik jika pada siklus I sebanyak 16 mahasiswa $(43,2 \%)$ maka setelah siklus II dilaksanakan berkurang hanya tinggal 4 mahasiswa saja $(10,8 \%)$. Dari hasil paparan tersebut dan sesuai dengan indikator yang ditetapkan pada penelitian ini, maka penelitian ini dikatakan berhasil.

\section{SIMPULAN}

Berdasarkan dari hasil penelitian di atas, dapat disimpulkan bahwa :

1. Kegiatan mentoring (pendampingan) dapat meningkatkan hasil belajar mahasiswa PGSD FIP UNIMED pada mata kuliah profesi pendidikan

2. Peningkatan kemampuan mahasiswa PGSD FIP UNIMED dapat dilihat dari hasil perolehan kemampuan mahasiswa mulai dari pra tindakan hingga siklus II selesai dilakukan dimana mahasiswa yang mendapatkan nilai kategori baik jika pada pra tindakan sebanyak sebelas mahasiswa $(29,7 \%)$ dan yang memperoleh nilai tidak baik sebanyak 26 mahasiswa (70,1\%) maka setelah dilaksanakan siklus I mahasiswa yang memperoleh nilai baik meningkat menjadi 21 mahasiswa $\quad(56,7 \%)$ dan mahasiswa yang memperoleh nilai tidak baik berkurang menjadi 16 mahasiswa $(43,2 \%)$.
Selanjutnya siklus II dilaksanakan dengan hasil jika pada siklus I jumlah mahasiswa yang memperolh nilai baik sebannyak 21 mahasiswa $(56,7 \%)$ maka pada siklus II meningkat menjadi 33 mahasiswa $(89,2 \%)$ sedangkan mahasiswa yang memperoleh nilai tidak baik jika pada siklus I sebanyak 16 mahasiswa $(43,2 \%)$ maka setelah siklus II dilaksanakan berkurang hanya tinggal 4 mahasiswa saja $(10,8 \%)$.

Adapun saran dalam penelitian ini ialah:

1. Untuk melaksanakan kegiatan mentoring (pendampingan) memerlukan persiapan yang cukup matang, sehingga dosen (peneliti lain) harus mampu menentukan berbagai hal yang mendukung kegiatan mentoring (pendampingan) sehingga diperoleh hasil yang optimal.

2. Perlu adanya penelitian yang lebih lanjut, karena hasil penelitian ini hanya dilakukan pada mahasiswa PGSD FIP UNIMED Tahun 2016.

\section{DAFTAR RUJUKAN}

Jihad. 2008. Perancangan dan Implementasi Perangkat Ajar Geometri SMTA. Tesis tidak diterbitkan. Jakarta: PPS UI.

Muhibbin, Syah. (2006). Perencanaan Pembelajaran: Mengembangkan Standar 
Kompetensi Guru. Bandung:

PT Remaja Rosdakarya.

Soepomo, P. 2008. Penanggulangan Mikonsepsi Bangun Datar Jajar Genjang Dan Belah Ketupat Di SLTPN 1 Binjai. Jurnal Penelitian bidang pendidikan :12 (2) Maret :157-167.

Suprijono. 2008. Pengembangan Paket Pembelajaran Berbantuan Komputer Materi Luas dan Keliling Segitiga untuk Kelas V Sekolah Dasar.

Syaodih dan Sumantri. (2004) Pembahasan Pembelajaran di SD Jakarta: Universitas Terbuka. 